\title{
Mudança estrutural e expansão produtiva da economia gaúcha no período 1998-2008: uma análise de Insumo-Produto
}

Henrique Morrone

\begin{abstract}
Resumo: O objetivo deste trabalho é verificar empiricamente o papel dos setores na economia gaúcha, bem como investigar as fontes das mudanças estruturais da economia gaúcha no período 1998-2008. Para isso, emprega-se os dados das matrizes de insumo-produto (MIP) de 1998 e 2008 da Fundação de Economia e Estatística do Rio Grande do Sul (FEE-RS) a fim de verificarmos a direção do movimento de mudança estrutural, bem como seus fatores explicativos. A técnica de decomposição estrutural de insumo-produto foi utilizada para acessar a contribuição dos efeitos das variaçoes da demanda final e da razão insumo-produto na explicação do crescimento da produção. Os resultados indicam que as variações da demanda final explicam a maior partedo crescimento da produção setorial, deixando o efeito das variações de insumo-produto com um papel marginal nesse processo. As análises mostram também que os diferenciais nas taxas de crescimento da produção dos setores também devem-se preponderantemente às variações da demanda final. As estimações apontam à mudança estrutural em direção à agropecuária, indicando um papel ativo do setor como propulsor do crescimento econômico estadual.
\end{abstract}

Palavras-chave: Matriz de Insumo-Produto;decomposições de insumo-produto; desenvolvimento regional.

Classificação JEL: O1, O140, R1.

Structural change and productive expansion of the state's economy in the period1998-2008: An input-output analysis

\begin{abstract}
This article aims to investigate the sources of structural change in the Rio Grande do Sul state economy during the 1998-2008 period. We employ data of inputoutput matrices (MIP) from 1998 and 2008. We employ the statistics from the Economics and Statistics Foundation (FEE-RS) in order to verify the direction of structural change as well as their explanatory factors. The input-output decomposition technique was used to access the contribution of the variations in final demand and input-output ratio in explaining economic expansion. The results indicate that variations in the final demand explain most of the growth of sectoral output, leaving the input-output effect with a marginal role in this process. The analysis also shows that the differences in
\end{abstract}

1 Doutor em Economia pela University of Utah. Professor Adjunto do Departamento de Economia e Relações Internacionais da Universidade Federal do Rio Grande do Sul. E-mail: hmorrone@ hotmail.com. 
growth rates of production are substantially determined by changes on final demand. Our estimates point to a structural transformation towards the agriculture, indicating an active role of this sector as an engine of economic growth.

Key-words: Input-output matrix, input-output decomposition, regional development.

\section{Introdução}

O presente artigo tem como objetivo geral investigar o papel dos setores e examinar as fontes das mudanças estruturais na economia do Rio Grande do Sul entre 1998 e 2008. Especificamente, pretende-se analisar o processo de mudança estrutural através da técnica de decomposição estrutural de insumo-produto.

Entre 2003 e 2014, o crescimento da economia brasileira foi baseado na expansão do consumo interno. Três medidas foram fundamentais nesse sentido. A primeira foi a decisão do governo brasileiro em adotar um plano voltado para o desenvolvimento econômico. O Plano de Aceleração do Crescimento (PAC) representou a retomada do papel do estado no planejamento econômico e na coordenação dos investimentos públicos e das empresas estatais e privadas. A segunda foi a implementação de políticas redistributivas, como a bolsa família, a elevação real do salário mínimo (que teve efeitos sobre os empregados e os aposentados, em particular, da previdência rural), que teve importantes efeitos no crescimento do consumo das familias e no aumento da atividade econômica. A terceira foi a expansão na oferta de crédito nos mais diversos segmentos do mercado financeiro. Esta foi liderada principalmente pelos bancos públicos que desempenharam o papel de líderes no processo de expansão do crédito. Com o aumento na oferta de crédito de bancos públicos e privados, o montante de crédito em relaçao ao PIB aumentou substancialmente de 2000 para 2010.

Ademais, o cenário internacional prevalecente até 2008 contribuiu para os resultados observados no Brasil. A economia mundial cresceu rapidamente, impulsionada pela China e Índia. O Brasil se beneficiou com o aumento da quantidade exportada e preços internacionais muito favoráveis nos primeiros anos da década. Houve redução da vulnerabilidade aos choques internacionais. Além disso, o país tornou-se um grande receptor de investimento direto líquido. A crise internacional ocorreu quando o Brasil detinha elevado volume de reservas e capacidade de fazer políticas anticíclicas.

Nesse contexto, a economia gaúcha se inseriu num ambiente nacional e internacional propício ao crescimento produtivo. As condições externas eram favoráveis ao crescimento nesse período, havendo espaço para políticas heterodoxas de desenvolvimento econômico. Conforme a visão estruturalista, desenvolvimento 
econômico envolve um processo permanente de mudança estrutural em direção a atividades dinâmicas, possuidoras de retornos crescentes de escala, principlamente a manufatura. Prebisch (1959), Kaldor (1975), e Rada e Taylor (2006) formularam teorias em que a manufatura assume papel central como motor do crescimento das nações. $O$ processo de transformação estrutural do sistema produtivo levará à transferência intersetorial de mão de obra, impactando a economia. Em primeiro lugar, haverá o estímulo da demanda, uma vez que os trabalhadores da indústria recebem maiores salários. Em segundo, o aumento da renda dos trabalhadores alterará o padrão do consumo em favor de bens industriais, o qual incentivará a produção industrial. Por fim, o crescimento da demanda e da produção industrial, devido às economias de escala presentes no setor, engendrará o aumento da produtividade da economia. Por ser uma atividade intensiva em capital, a indústria é capaz de tornar cada trabalhador transferido mais produtivo.

O crescimento desigual dos setores também foi investigado por autores de outras correntes do pensamento econômico. Um dos pioneiros foi Kuznets (1966). Ele argumenta que crescimento econômico, independente do nível inicial de desigualdade, pode levar a igualdade de renda no longo prazo. Nesse sentido, a Curva de Kuznets sustenta que em estágios iniciais a desigualdade seria pró-crescimento. A curva de Kuznets, em forma de "U" invertido, estabelece uma forte evidência empírica de que nos estágios intermediários de desenvolvimento o aprofundamento da desigualdade seria necessária e um fenômeno natural. Seria uma consequência natural do processo de crescimento econômico, enquanto no longo prazo formas igualitárias predominariam. $\mathrm{O}$ argumento é de que o crescimento do tamanho relativo da indústria geraria o crescimento da produtividade, levando ao crescimento da remuneração dos trabalhadores especializados. A escassez de trabalhadores qualificados e de capital causaria o aumento da remuneração dos mesmos nos estágios iniciais e intermediários do desenvolvimento. Ao longo do tempo, a oferta de trabalhadores qualificados aumentaria e, consequentemente, sua remuneração tenderia a decrescer, reduzindo o grau de desigualdade da economia. Piketty (2014), contudo, refuta a curva de Kuznets argumentando que uma distribuição mais igualitária não seria uma tendência predominante de longo prazo do capitalismo. Ele analisou o caplitalismo desde seu inicio até seu atual estágio, denominado capitalismo financeiro. Seu estudo, bastante influente, examinou dados mundiais sobre distribuição da riqueza e renda, especialmente das economia norte-americana e francesa, mostrando que não existe evidência empírica de aumento da igualdade. Seu rigoroso trabalho projeta o aumento da desigualdade, tendo as heranças um papel cada vez maior na explicação da renda e riqueza.

De forma alternativa e seguindo a abordagem neoclássica, Baumol (1967) sustenta que os setores cresceriam de forma desigual devido a disparidades de progresso técnico. Nesse sentido, a manufatura por ser uma atividade dinâmica incorreria em ganhos de produtividade, enquanto nos serviços (setor intensivo em trabalho) a produtividade cresceria lentamente. Como resultado, os setores menos produtivos 
(os serviços) usariam uma maior parcela dos insumos na economia, engendrando numa maior parcela no valor do produto nacional. Esse fenômeno no qual o setor de serviços compartilha os ganhos de produtividade da manufatura via aumento de seus preços ficou conhecido na literatura como Baumol disease.

Diante do exposto, o presente artigo tem por objetivo principal verificar a direção e as fontes causadoras das mudanças estruturais da economia gaúcha no período 1998-2008. Tendo em vista que esse período foi marcado por mudanças substanciais na economia nacional (uma maxidesvalorização em 1999, a introdução de um modelo de desenvolvimento mais inclusivo em meados de 2002, e uma crise do subprime em 2007/2008), espera-se que nesses 10 anos tenha ocorrido uma transformação estrutural significativa da economia gaúcha. Essas mudanças afetaram as economias regionais de forma assimétrica. Ademais, a economia do Rio Grande do Sul é mais sensível a variações da taxa de câmbio que a média brasileira. Isso conjuntamente justifica a incursão investigativa do presente artigo. Estudo semelhante foi aplicado ao Brasil entre 1949/2010 e seus subperíodos de 11 anos (1949-1959, 1959-1970, 1980-1990, 1990-2000, e 2000-2010) por Berni (2006) a fim de examinar o processo de mudança estrutural e decomposição do crescimento em efeito demanda e efeito produtividade dos insumos intermediários. O presente artigo foi fortemente influenciado por Berni (2006) e Messa (2013). Especificamente, pretende-se estimar, com base nas Matrizes de Insumo-produto do RS para os anos de 1998 e 2008, a contribuição dos efeitos da demanda final e da razão insumoproduto para o crescimento da produção setorial.

A fim de proceder as estimações e analisar os resultados, inicialmente, estimou-se duas MIPs (11x11) a partir da Tabela de Recursos e Usos (TRU) para os anos de 1998 e 2008 da Fundação de Economia e Estatística do Rio Grande do Sul (FEE-RS). Nesse sentido, existiu a necessidade de se fazer a agregação da TRU, pois a mesma está estruturada com 40 atividades e 66 produtos. Seguiu-se o estabelecido pela Classificação Nacional de Atividades Econômicas (CNAE) do Instituto Brasileiro de Geografia e Estatística (IBGE) no processo de agregação para chegarmos à MIP (11x11). A Matriz (11x11) será a base para as estimações, representando o lado real da economia. O presente artigo tenta contribuir ao examinar o processo de mudança estrutural da economia gaúcha ocorrido no período.

$\mathrm{O}$ artigo está estruturado como segue. Na próxima seção, apresenta-se uma breve revisão da literatura. A seção 3 apresenta os dados e a metodologia. Os resultados das estimações são apresentados na seção 4 . Por fim, a seção 5 reserva-se às conclusões. A MIPs do RS de 1998 e 2008 estão dispostas no Apêndice.

\section{0 papel da agricultura, da indústria, e dos serviços na economia e modelos de análise regional: Uma breve revisão}

A agricultura, a indústria e os serviços são atividades centrais para o desenvolvimento econômico. A agricultura apresenta potencial de setor indutor da demanda, 
estimulando também economias de escala para a indústria. Esse setor desempenha um papel diferenciado em países em desenvolvimento, onde as divisas decorrentes das exportações viabilizam as importações de máquinas. Ademais, a agricultura funciona como um reservatório de mão de obra em economias de renda baixa e média, aumentando seu emprego em períodos de recessivos e diminuindo em momentos de expansão (RADA, 2010). Para acelerar a industrialização torna-se importante a presença de um setor agrícola que forneça alimentos de baixo custo, do contrário o processo de industrialização pode ser abortado (HARRIS; TODARO, 1970; LEWIS, 1954; VON ARNIM; RADA, 2011). Nesse sentido, Lewis (1954) afirma que desenvolvimento requer o crescimento da produtividade da agricultura. Assim, o setor agrícola apresentaria um papel funcional e passivo no processo de desenvolvimento das economias.

Para Kaldor (1968), a indústria, principalmente a manufatura, é o motor do crescimento econômico. Kaldor elencou três leis de crescimento (THIRLWALL, 1983), que representariam o processo de crescimento e dinâmica dos países. Sua primeira lei relacionou o crescimento da produção manufatureira com o crescimento do Produto Nacional Bruto (PNB). De acordo com essa, Existia uma relação positiva entre essas variáveis. Nesse sentido, segundo Feijó e Carvalho (2002), dois elementos seriam responsáveis pelo crescimento do produto agregado. $\mathrm{O}$ primeiro seria o peso do setor na produção da economia e o segundo seria a sua taxa de crescimento. O efeito total seria o resultado da multiplicação de ambos.

Em sua segunda lei, foi observada uma relação positiva e forte entre o crescimento da produtividade da indústria com o crescimento de sua produção. Nesse caso, a demanda estimularia o aumento da produção, aumentando a produtividade em atividades detentoras de retornos crescentes de escala. Assim, o crescimento da produtividade seria endógeno, sendo determinado pela demanda.

Por fim, sua terceira lei encontrou uma relação positiva entre o crescimento da produtividade da economia com o emprego industrial e a produção industrial manufatureira. Segundo essa lei, existiria uma relação negativa entre a produtividade do trabalho agregada e a o crescimento do emprego não industrial.

A explicação para a lei estaria no fato de que quanto maior o crescimento da produção manufatureira, maior será a transferência de trabalhadores dos demais setores à manufatura. Parte-se do pressuposto de que a mão de obra empregada nos demais setores é redundante.

$\mathrm{Da}$ exposição dessas leis, observa-se uma consistência interna entre elas. $\mathrm{O}$ crescimento do produto industrial estimularia o incremento da produtividade industrial (pela segunda lei), que, devido à migração da mão de obra à indústria, engendraria o crescimento da produtividade do trabalho não industrial (MAMGAIN, 1999). O processo de causação circular cumulativa pode ser descrito conforme Stafford (1989): o crescimento da demanda causaria maior produção, estimulando o aumento da produtividade, o que afetaria positivamente a demanda. Em síntese, Kaldor (1975) afirma que a demanda doméstica e externa por manufaturas estimu- 
laria o crescimento da produtividade dos países. Nesse contexto, o setor industrial seria central para promover um crescimento sustentável.

Por fim, recentemente o setor de serviços tem sido elencado como sendo uma atividade com potencial para estimular o crescimento. Dasgupta e Singh (2005) apontam que esse setor pode promover um processo de crescimento pujante. Há duas interpretações possíveis para o papel dos serviços na economia. Na primeira, o os serviços são vistos como uma extensão da manufatura, atuando de forma subordinada ao crescimento manufatureiro. Kaldor (1968) e Chang (2011) indicam a existência dessa dependência dos serviços com relação à manufatura. Em contraste, a segunda interpretação salienta que os serviços lideram o processo de desenvolvimento de uma economia, substituindo a manufatura (DASGUPTA; SIN$\mathrm{GH}, 2005)$. Os serviços liderariam o crescimento econômico das economias, pois eles têm se tornado cada vez mais tradables, exibindo economias de escala. Nesse contexto, o crescimento indiano confirmaria o argumento em favor dos serviços. Em síntese, os serviços desempenhariam um papel ativo ou passivo no processo de desenvolvimento econômico. Contudo, seria importante diferenciar os serviços high tech, altamente produtivos, dos serviços de baixa produtividade, atividades preponderantes em países de renda baixa e média, a fim de melhor compreender suas funções na expansão do nível de atividade econômica.

\subsection{Modelos de Análise Regional}

A literatura envolvendo técnicas de análise regional é bastante vasta. Nesta breve subseção, trataremos de apenas três técnica aplicadas à economia: Shift-share, decomposições do crescimento à la Divisia (1926) e decomposições de insumo-produto. Um dos trabalhos pioneiros no Brasil foi o de Lodder (1972) que decompôs o crescimento do emprego nos estados em dois períodos: 1940-1950 e 1950-1960. Ele examinou a evolução de 30 atividades para os estados brasileiros. Observou que até 1960 a atividade agropecuária seria a principal responsável pelo desempenho agregado dos estados, ressaltando a centralidade desse setor.

Para o Rio Grande do Sul, um dos primeiros estudos a aplicar a técnica ShiftShare foi Souza (1981). O autor analisa o comportamento da indústria de transformação gaúcha do ano inicial de 1975 a 1979. Souza verificou que os segmentos industriais que exibiram crescimento mais robusto foram: fumo, bebidas, minerais não-metálicos, mobiliário, química, vestuário, editorial e borracha. A região de Porto Alegre apresentou um desempenho bastante positivo, sendo o produto do deslocamento industrial para essa região. Souza (2004) utilizou os dados da RAIS e a mesma metodologia para averiguar a evolução dos municípios da região metropolitana de Porto Alegre. Concluiu que a cidade estaria exibindo um processo de desindustrialização acelerado derivado possivelmente da presença de deseconomias externas.

Em um estudo recente, Torres et al. (2013) empregaram a técnica Shift-share para os subsetores da indústria do Rio Grande do Sul entre 1996 e 2007. Separando 
a amostra em três subperíodos (1996-1998, 1999-2001 e 2005-2007), os autores usaram as estatísticas da Pesquisa Indústria Anual das empresas (PIA-empresa) para explicar a diminuição da participação da indústria estadual na indústria nacional. Apesar da performance positiva da indústria entre 1996 e1998, o desempenho industrial apresentou uma deterioração nos demais períodos. Uma das explicações sugeridas pelos autores seria a inexistência dos segmentos industriais mais dinâmicos na economia do Rio Grande do Sul. O estado apresentou perda de vantagens competitivas nos períodos: 1999- 2001 e 2005-2007.

Além das análises através do método shift-share, outro procedimento bastante empregado é a abordagem insumo-produto. Hewings et al. (1989) realiza uma avaliação dos métodos tradicionais para detectar mudança estrutural e setores chave das economia empregando matrizes de insumo-produto. Para tal, emprega as matrizes de insumo-produto brasileiras para os anos de 1959, 1970 e 1975 . A principal contribuição do estudo é a comparação das técnicas tradicionais com abordagens alternativas. Berni (2006) procedeu uma análise estrutural por meio de decomposições de insumo-produto para a economia brasileira entre 1949 e 2010, contemplando também seus subperíodos de 11 anos de intervalo, a fim de detectar mudança estrutural e setores dinâmicos da economia. Para isso, empregou as matrizes de insumo-produto de 1949, 1959, 1970, 1980,1990, 2000 e uma projeção para 2010. Seu principal resultado foi a constatação de que apenas os setores de transformação de bens de produção e os serviços apresentaram crescimento do emprego e da produtividade no período como um todo. Na mesma linha, Guilhoto et al. (2001), empregando a mesma abordagem, compara as mudanças estruturais das economias norte-americana e brasileira. Os resultados da pesquisa confirmam o papel central da demanda como fator explicativo da mudança estrutural das economias.

Messa (2013) examina as fontes das mudanças estruturais ocorridas na economia brasileira durante os anos 2000. Para tal, o autor emprega as decomposições estruturais de insumo produto. Os resultados do estudo mostram que grande parte do diferencial de crescimento ocorrido entre a indústria e os serviços entre o ano 2000 e 2009 pode ser creditada à queda do consumo intermediário de insumos industriais, sendo esta substituída pelo incremento no consumo intermediário de serviços.

Por fim, uma técnica bastante empregada internacionalmente é a técnica de decomposições do crescimento baseada no trabalho de Divisia (1926) e Ocampo et al. (2009). Esse método é empregado a fim de analisar a contribuição dos setores para o crescimento do produto e da produtividade agregada. No que tange ao crescimento do produto, a contribuição dos setores ao crescimento agregado dependerá do peso do setor no total e de sua taxa de crescimento. Nessa linha, essa técnica pode complementar as análises efetuadas pelos métodos shift-share e insumoproduto. Dois estudos aplicados internacionalmente e relativamente recentes nesse tema são Rada e Taylor (2006) e Roncolato e Kucera (2013). 


\section{Dados e Metodologia}

A Matrizes de Insumo-Produto (MIP-RS) da economia gaúcha para os ano de 1998 e 2008, da Fundação de Economia e Estatística do Rio Grande do Sul (FEE$\mathrm{RS}$ ), foram empregadas como base de dados para nossas estimações. Utilizaram-se as matriz setor por setor, agregando-as para 11 atividades produtivas.

A primeira etapa do estudo consistiu na construção das matrizes a partir da Tabela de Recursos e Usos. Para isso, utilizaram-se os procedimentos desenvolvidos por Grijó e Berni (2006). Tendo-se definido os setores produtivos, efetuamos a agregação da TRU $(66 \times 40)$ numa TRU $(11 \times 11)$. As novas TRUs com apenas 11 produtos e 11 atividades representaram o ponto de partida para as estimações. Nesse estágio do trabalho, foram empregados os métodos de insumo-produto a fim de produzirmos matrizes de insumo-produto a partir dos dados das TRUs.

$\mathrm{Na}$ segunda parte, empregamos a técnica de insumo-produto a fim de examinarmos as contribuições dos efeitos de demanda e da razão de insumo-produto na explicação do crescimento do valor da produção setorial entre os dois períodos base (1998-2008). Nesse estágio, realizou-se o deflacionamento dos valores da produção de 2008 através do deflator implícito do valor adicionado setorial divulgado pela FEE-RS.

Abaixo, apresentamos o procedimento de decomposição de insumo-produto. Assim, poderemos investigar as fontes causadoras do crescimento do valor da produção.

$\mathrm{O}$ modelo de insumo-produto tem origens pré-clássicas que remontam ao trabalho dos Fisiocratas. Em sua forma mais simples o modelo de Leontief pode ser apresentado como segue.

O elemento central do modelo é a existência de uma relação estável entre os bens intermediários e a produção total das atividades. A partir desse momento, ele chega ao conceito de coeficiente técnico de produção $\left(z_{i j}\right)$, uma proxy da tecnologia da economia.

$$
z_{i j}=g_{j} / g_{j} \text {. }
$$

Sendo:

$g_{i j}$ : o valor que o setor i vendeu para o setor $\mathrm{j}$;

$g_{j}$ : o valor bruto da produção do setor $\mathrm{j}$;

$z_{i j}$ : o valor consumido pela atividade $\mathrm{j}$ proveniente da atividade $\mathrm{i}$ a fim de produzir uma unidade monetária.

Essa relação, bem como todo o modelo depende da existência da Tabela de Recursos e Usos (TRU), fonte essencial para a construção das MIPs. Como esses dados estão disponíveis de forma defasada, podemos passar para a explicação dos próximos elementos do modelo de Leontief. Desse modo, podemos examinar a linha da MIP e chegar às seguintes relações:

$$
g_{i}=\sum_{j} g_{j}+f_{i}
$$


Sendo:

$f_{i}$ : demanda final do setor $\mathrm{i}$.

Com um pouco de manipulação, temos:

$$
g_{i}=\sum_{j} z_{j} g_{j}+f_{i}
$$

Por fim, usando representação matricial, é possível reescrever a Equação (3) como:

$$
\begin{gathered}
g=Z g+f, \\
g=(I-Z)^{-1} f .
\end{gathered}
$$

A matriz Z é a matriz de coeficientes técnicos diretos, ela mede apenas impactos diretos nas atividades. A matriz (I-Z) ${ }^{-1}$ é a matriz de Leontief, que representa os coeficientes técnicos diretos e indiretos. $\mathrm{O}$ modelo de insumo-produto, apresentado na Equação (5), informa a produção (g) necessária para atender um determinado incremento na demanda final (f).

De posse de duas matrizes insumo-produto de 1998 e 2008, pode-se obter a decomposição do crescimento da produção. Para tal, procedemos do seguinte modo proposto por Feijo e Ramos (2013). Primeiro, a variação no valor da produção pode ser dividida em dois componentes: variação na demanda final e variação nos coeficientes técnicos. A variação na produção entre os período 0 e 1 pode ser expressa na seguinte forma:

$$
\pi_{1} g_{1}-g_{0}=\pi_{1} Z_{1} f_{1}-Z_{0} f_{0}
$$

Sendo $\pi_{1}$ o deflator implícito do valor adicionado. Somando e subtraindo o termo $\mathrm{Z}_{1} \mathrm{f}_{0}$, a Equação (6) permanece inalterada e podemos acessar alguns resultados interessantes.

$$
\begin{array}{r}
\pi_{1} Z_{1} f_{1}-Z_{0} f_{0}=\left(\pi_{1} Z_{1} f_{1}-Z_{1} f_{0}\right)+\left(Z_{1} f_{0}-Z_{0} f_{0}\right) \\
\pi_{1} Z_{1} f_{1}-Z_{0} f_{0}=\left(\pi_{1} f_{1}-f_{0}\right) Z_{1}+\left(Z_{1}-Z_{0}\right) f_{0}
\end{array}
$$

As Equações (7) e (8) explicam a variação na produção em dois componentes. O primeiro termo do lado direito da equação expressa a variação na produção devida à demanda final. O segundo fator do lado direito, mostra a variação na produção provocada pela variação nos coeficientes técnicos. 
Assim, observa-se que a decomposição da variação da produção em seus componentes é bastante simples e funcional, auxiliando no entendimento da estrutura produtiva estadual. A proxima seção, analisará os resultados para essas estimações em detalhe.

\section{Resultados}

As estimações das decomposições do crescimento do valor da produção através das técnicas de insumo-produto são importantes para o maior entendimento das fontes causadoras do crescimento estadual.

A Tabela 1 apresenta as taxas de crescimento dos setores e subsetores da economia gaúcha entre 1998 e 2008. Dentre os setores que apresentaram o maior crescimento estão a agropecuária e a indústria. Quanto aos subsetores, se destacam as seguintes atividades: indústrias de transformação e extrativa $(82,45 \%)$, produção e distribuição de eletricidade e gás $(88,21 \%)$, intermediação financeira $(88,27 \%)$ e outros serviços $(162,06 \%)$. O resultado para os serviços de informação também foi positivo, embora tenhamos que ter cautela em sua interpretação dada a inexistência de deflatores adequados para o setor ${ }^{2}$. Para maiores detalhes, ver Tabela 1.

Tabela 1: Crescimento da produção setorial gaúcha 1998-2008.

\begin{tabular}{l|c|l|c}
\hline Setor & $\begin{array}{c}\text { Crescimento } \\
(\%)\end{array}$ & \multicolumn{1}{|c|}{ Atividade } & $\begin{array}{c}\text { Crescimento } \\
(\%)\end{array}$ \\
\hline Agropecuária & 70,82 & Agropecuária & 70,82 \\
\hline Indústria & 62,14 & Indústria de transformação e ind. extrativa & 82,45 \\
& & Produção e distrib. de eletricidade e gás, água & 88,21 \\
& & Construção civil & $-38,76$ \\
\hline Serviços & \multirow{2}{*}{34,01} & Comércio e Serviços de Manutenção e Reparação & 35,79 \\
& & Transporte, armazenagem e correio & 67,69 \\
& & Serviços de informação & 131,44 \\
& & Intermediação financeira, seguros e previdência & 88,27 \\
& & Atividades imobiliárias e aluguéis & $-22,08$ \\
& & Administração, saúde e educação públ. e seg. soc & 28,54 \\
& & Outros serviços & 162,06 \\
\hline
\end{tabular}

Fonte: Elaboração dos autores.

No que tange aos resultados encontrados para a decomposição das taxas de crescimento, dispostos na Tabela 2 , três conclusões principais podem ser derivadas. Primeiro, tanto a nível setorial quanto a subsetorial o efeito das variações da demanda final foram importantes na explicação do crescimento da produção. Por exemplo, 97,93\% da

2 Para o deflacionamento dos dados da atividade serviços de informação foi utilizado o deflator implícito do PIB gaúcho, exigindo cautela na análise dos resultados. 
taxa de crescimento da produção agropecuária no período foi explicada pelas variações na demanda final, sendo apenas 2,07\% explicados por mudanças nos coeficientes técnicos. Isto indica a centralidade da demanda como indutora da mudança estrutural. Para todos os setores e subsetores analisados, os efeitos da variação dos coeficientes (razão insumo-produto) como indutores da produção foram secundários.

Segundo, a relação insumo-produto contribuiu para a contração de um importante subsetor da indústria: a produção e distribuição de eletricidade e gás. $\mathrm{Ou}$ seja, uma redução no consumo intermediário dos produtos ofertados pela ativividade de produção e distribuição de eletricidade e gás engendrou um decréscimo no produto dessa atividade de $23,17 \%{ }^{3}$. Alternativamente, o efeito insumo-produto conteve uma queda mais acentuada da construção civil. Houve uma contribuição para o crescimento desse setor, possivelmente via ganhos de produtividade, no montante de 2,63\% $\%^{4}$. No agregado, a relação insumo-produto, em termos líquidos, auxiliou para o crescimento de $7,42 \% 5$ do setor industrial.

De forma análoga, a variação dos coeficientes técnicos foi responsável pela queda de 10,97\% do subsetor outros serviços. Logo, a redução do consumo intermediário ofertado por essa atividade contribuiu negativamente para o seu desempenho. Isto levou a uma contribuição negativa para o crescimento da produção do setor serviços, porém insuficiente para conter a expansão do setor que foi preponderantemente puxada pela demanda final.

Tabela 2: Decomposição do crescimento da produção setorial em efeitos de demanda e efeitos da razão insumo-produto para a produção setorial gaúcha no período 1998-2008.

\begin{tabular}{lcc}
\hline \multirow{2}{*}{ Setor } & \multicolumn{2}{c}{ Efeitos (\%) } \\
\cline { 2 - 3 } & demanda final & razão insumo-produto \\
\hline Agropecuária & 97,93 & 2,07 \\
Indústria & 88,05 & 11,95 \\
Serviços & 99,94 & 0,06 \\
\hline Subsetores & & \\
Agropecuária & 97,93 & 2,07 \\
Indústria de transformação e indústria extrativa & 86,99 & 13,01 \\
Produção e distribuição de eletric. e gás, água, esgoto e limp. urbana & 126,27 & $-26,27$ \\
Construção civil & 106,78 & $-6,78$ \\
Comércio e Serviços de Manutenção e Reparação & 98,88 & 1,12 \\
Transporte, armazenagem e correio & 91,25 & 8,75 \\
Serviços de informação & 68,84 & 31,16 \\
Intermediação financeira, seguros e previdência compl. e serviços & 117,68 & $-17,68$ \\
Atividades imobiliárias e aluguéis & 123,62 & $-23,62$ \\
Administração, saúde e educação públicas e seguridade social & 96,70 & 3,30 \\
Outros serviços & 106,77 & $-6,77$ \\
\hline
\end{tabular}

Fonte: Cálculos dos autores.

$88,21 \%$ (Tabela 1$) \times(-26,27 \%)$ (Tabela 2$).$

$4 \quad(-38,76)$ (Tabela 1) x $(-6,78)$ (Tabela 2).

$5 \quad 62,14 \%$ (Tabela 1$) \times(11,95 \%)$ (Tabela 2$)$. 
No nível setorial, a Figura 1 mostra resumidamente a contribuição dos efeitos demanda final e insumo-produto na explicação do crescimento do valor da produção setorial. Nela, observa-se que a demanda final foi responsável pela indução do crescimento da produção conforme anteriormente citado. Assim, a demanda final engendrou um crescimento da agropecuária $(69,35 \%)$, da indústria $(54,72 \%)$ e dos serviços $(33,99 \%)$.

Figura 1. Contribuição dos efeitos demanda final e parcela insumo produto para o crescimento da produção setorial gaúcha (\%).

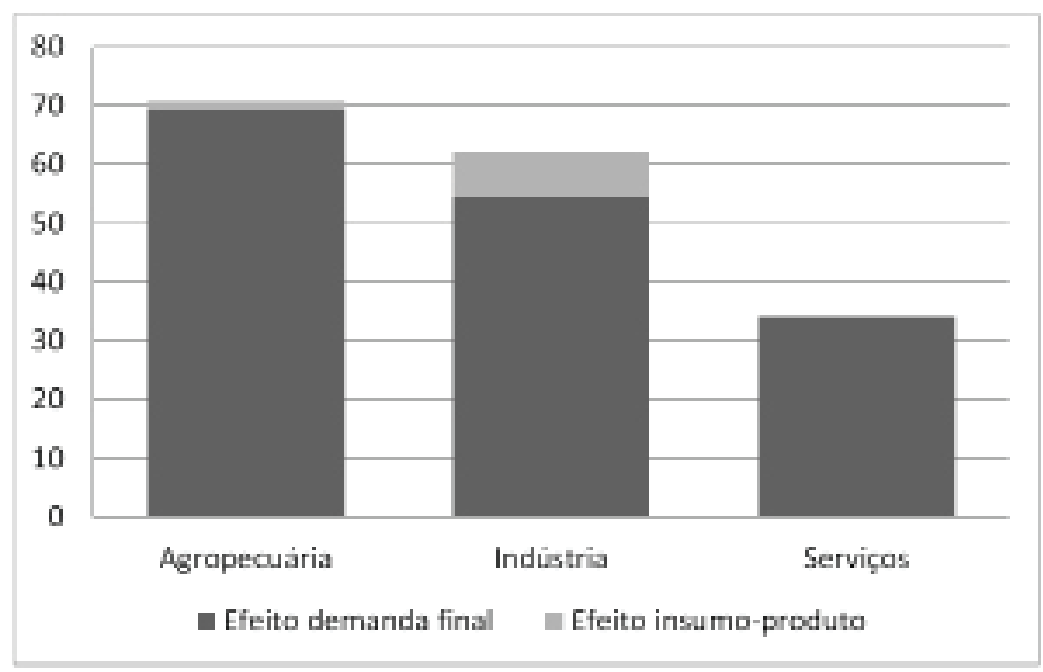

Fonte: Elaboração dos autores.

Por fim, deve-se investigar a dinâmica relativa dos setores da economia. Nesse sentido, pode-se inferir que o crescimento diferencial da agropecuária para a indústria de $14,63 \%{ }^{6}(168,70 \%$ da diferença de crescimento) deve-se majoritariamente à variação da demanda final, sendo o restante explicado pela parcela insumo-produto (-68,70\%). Já o crescimento diferencial entre a indústria e os serviços se deve $7,4 \%$ (26,32\% da diferença) a relações insumo-produto e $20,73 \%$ (73,68\% da diferença) de efeitos induzidos pela demanda.

Em linhas gerais, o efeito das variações da demanda final dominou as alterações na parcela insumo-produto para a explicação do crescimento da produção das atividades da economia estadual. Além disso, as diferenças no crescimento entre os setores também é majoritariamente explicada pela demanda final, deixando a relação insumo-produto com um papel secundário. A mudança estrutural da economia gaúcha em direção à agropecuária fica evidente quando se analisa as taxas de cres- 
cimento dos setores. Isto poderia contribuir para a expansão do nível de atividade econômica regional dadas as vantagens comparativas do estado na produção agrícola e suas fortes relações com a agroindústria.

Desde 2003, a indústria nacional e regional foi impactada negativamente por uma apreciação cambial substancial e um aumento da demanda de commodities por parte da China. Esses dois fatores contribuíram para a desarticulação do setor industrial. $\mathrm{O}$ fenômeno da desindustrialização regional tem sido enfatizado em estudos como, por exemplo, Bender Filho (2013).

\section{Considerações Finais}

O presente estudo empregou a técnica de insumo-produto a fim de decompor o crescimento da produção setorial da economia gaúcha. Estimar os efeitos indutores da demanda final e da relação insumo-produto na produção estadual é importante para o maior entendimento da evolução da economia gaúcha. As MIPs do RS para os anos de 1998 e 2008 foram utilizadas para verificar os fatores explicativos do processo de mudança estrutural da economia.

Os resultados para as decomposições de insumo-produto mostram que tanto a nível setorial quanto a subsetorial o efeito das variações da demanda final foram preponderantes na explicação do crescimento da produção. Por exemplo, 97,93\% da taxa de crescimento da produção agropecuária no período 1998-2008 foi explicada pelas variações na demanda final, sendo apenas $2,07 \%$ induzidos por mudanças nos coeficientes técnicos. O mesmo ocorreu para os demais setores produtivos.

No que tange às diferenças de crescimento setoriais, as estimações mostram que essas se devem a variações da demanda final. Em especial, 73,68\% do diferencial de crescimento entre a indústria e os serviços (entre 1998 e 2008) é resultado dos efeitos da demanda final. Isto indica a primazia da demanda no processo de crescimento da produção estadual, deixando a parcela insumo-produto como um efeito secundário na explicação desse crescimento.

Pode-se concluir, portanto, que a demanda final assumiu a liderança no processo de mudança estrutural da economia gaúcha ocorrido entre 1998 e 2008. Observou-se a mudança estrutural em direção à agropecuária, indicando um papel ativo do setor como estimulador do aumento do nível de atividade econômica regional. O estado apresenta tradicionalmente vantagens comparativas na produção agrícola o que pode culminar em crescimento produtivo. Contudo, os encadeamentos produtivos para frente e para trás do setor (ver Tabela 5 do apêndice) são inferiores aos apresentados pela indústria manufatureira, fazendo com que a performance da economia gaúcha possivelmente siga uma trajetória second best. Assim, maiores incentivos à indústria de transformação tornam-se importantes a fim de promover o crescimento sustentável da economia gaúcha. Nesse quesito, o governo terá um papel fundamental na condução dos rumos da economia. 


\section{Referências}

BAUMOL, W. Macroeconomics of unbalanced growth: the anatomy o urban crisis. American Economic Review, v. 57, n. 3, p. 415-426, 1967.

BENDER FILHO, R. O risco de desindustrialização da economia gaúcha: uma análise do período de 1991 a 2010. Revista Indicadores Econômicos FEE, v. 41, n. 2, p. 67-76, 2013.

BERNI, D. Mudanças no padrão de uso da mão-de-obra no Brasil entre 1949 e 2010. Nova Economia, v. 16, n. 1, p. 139-172, 2006. crossrefhttps://doi.org/10.1590/ S0103-63512006000100004

CHANG, H.J. Manufacturing: statements, opening statements and manufacturing :statements,rebuttal statements. The Economist, 2011. Disponível em . Acesso em 20 de março de 2014.

DASGUPTA, S.; SINGH, A. Will services be the new engine of Indian economic growth? Development and Change, v. 36, n. 6, p. 1035-57, 2005.crossrefhttps:// doi.org/10.1111/j.0012-155X.2005.00449.x

DIVISIA, F. l'indice monétaire et la théorie de la monnaie. Revue d'Economie Politique, v. 39, p. 980-1008, 1926.

FEIJÓ,C., CARVALHO, P. Uma interpretação sobre a evolução da produtividade industrial no Brasil nos anos 90 e as "Leis de Kaldor". Revista Nova Economia, v. 12, n. 2, p. 57-78, 2002.

FEIJÓ, C. A.; RAMOS, R.; L. O. Contabilidade Social: A Nova Referência das Contas Nacionais do Brasil. Editora Campus, 2013.

FUNDAÇÃO DE ECONOMIA E ESTATÍSTICA (FEE/RS). 1995- 2010. Estatisticas econômicas. Governo do Rio Grande do Sul. Disponível em . Acesso em 10 de fevereiro de 2014.

GRIJÓ, E.; BERNI, D. A Metodologia Completa para a Estimativa de Matrizes de Insumo-Produto.Teoria e Evidência Empírica, v. 14, p. 9-42, 2006.

GUILHOTO, J.; HEWINGS, J. D.; SONIS, M.; GUO, J. Economic structural change over time Brazil and the United States compared. Journal of Policy Modeling, v. 23, n. 1, p. 703-711, 2001. crossrefhttps://doi.org/10.1016/S0161-8938(01)00094-1

HARRIS, J.R.; TODARO, M.P. Migration, unemployment and development: a two sector analysis. The American Economic Review, v. 60, n. 1, p. 126-42, 1970. 
HEWINGS, J. D.; FONSECA, M.; GUILHOTO, J.; SONIS, M. Key sectors and structural change in the Brazilian economy: A comparison of alternative approaches and their policy implications. Journal of Policy Modeling, v. 11, n. 1, p. 67-90, 1989. crossrefhttps://doi.org/10.1016/0161-8938(89)90025-2

Instituto Brasileiro de Geografia e Estatística (IBGE). "CNAE 2.0.” Governo Federal. http://www.ibge.gov.br/home/ (accesso em 8 September 2014).

KALDOR, N. Productivity and growth in manufacturing industry: a reply. Economica, new series, v. 35, n. 140, p. 385-91, 1968.

KALDOR, N. Economic growth and the Verdoorn Law. A comment on Mr. Rowthorn's article. Economic Journal, Cambridge, v. 85, p. 891-96, 1975. crossref https://doi.org/10.2307/2230633

KUZNETS, S. Modern Economic Growth: Rate, Structure and Spread. New Haven: Yale University Press, 1966.

LEWIS, W. A. Economic development with unlimited supplies of labour. Manchester School, v. 28, n. 2, p. 139-91, 1954. http://dx.doi.org/10.1111/j.1467- 9957.1954. tb00021.x

LODDER, C.A. Crescimento da ocupação regional e seus componentes. In: P.R. HADDAD (org.), Planejamento Regional: métodos e aplicação ao caso brasileiro. Rio de Janeiro, IPEA/INPES, p. 53-103, 1972.

MANGAIN, V. Are the Kaldor-Verdoorn laws applicable in the newly industrializing countries? Review of Development Economics, Oxford, v. 3, n. 3, p. 295-309, 1999. crossref https://doi.org/10.1111/1467-9361.00069

MESSA, A. Mudanças estruturais na economia brasileira ao longo da década de 2000. Revista de Economia Contemporânea, v. 17, n. 3, p. 452-467, 2013. crossref https://doi.org/10.1590/S1415-98482013000300003

MORRONE, H. O setor energético da economia setor energético da economia setor energético da economia gaúcha e suas relações intersetoriais: uma análise uma análise de insumo-produto. Revista Indicadores Econômicos FEE, Porto Alegre, v. 43, n. 1, p. 55-66, 2015.

OCAMPO, J.A.; C. Rada; L. Taylor. Growth and policy in developing countries: a structuralist approach. New York: Columbia University Press, 2009. 178 p. crossrefhttps://doi.org/10.7312/ocam15014 
PIKETTY, T. O capital no século XXI. Íntrinseca editora, 2014. 669 p.

PREBISCH, R. Commercial Policy in the Underdeveloped Countries. The American Economic Review, v. 49, n. 2, p.251-73, 1959.

RADA, C., TAYLOR, L. Developing and transition economies in the late 20th century: diverging growth rates, economic structures, and sources of demand. SCEPA Working Paper 2006-1. New School for Social Research, 2006.

RADA, C. Formal and informal sectors in China and India. Economic Systems Research, v. 22, n. 2, p. 315-341, 2010. crossrefhttps://doi.org/10.1080/09535314 .2010 .482924

RONCOLATO, L.; KUCERA, D. Structural drivers of productivity and employment growth: a decomposition analysis for 81 countries. Cambridge Journal of Economics, v. 38, n. 2, p. 399-424, 2013. crossrefhttps://doi.org/10.1093/cje/bet044

SÁ, R. de (Org.). Matriz de Insumo-Produto do Rio Grande do Sul: 2008. Porto Alegre: FEE, 2014. Disponível em: <http://www.fee.tche.br>. Acesso em: dez. 2014.

SOUZA, N. Estrutura espacial da indústria gaúcha, 1975-1979. Perspectiva Econômica, v. 11, n. 34, p. 39-100, 1981.

SOUZA, N. Dinâmica estrutural-diferencial da região metropolitana de Porto Alegre, 1990/2000. Revista de Economia, v. 30, n. 2, p. 121-144, 2004. crossref https:// doi.org/10.5380/re.v30i2.2017

STAFFORD, B. Deindustrialization in advanced economies. Cambridge Journal of Economics, v. 13, p. 541-54, 1989. crossrefhttps://doi.org/10.1093/oxfordjournals.cje.a035110

TORRES, P.G.; PALERMO, P.U.; PORTUGAL, M.S.O desempenho da indústria no Rio Grande do Sul, entre 1996 e 2007: uma análise comparada através do método Shift-Share. Revista Indicadores Econômicos FEE, v. 41, n. 1, p.:45-74, 2013.

THIRLWALL, A. P. A plain man's guide to Kaldor's growth laws. Journal of Post Keynesian Economics, New York, v. 5, n. 3, p. 345-358, 1983. crossrefhttps://doi. org/10.1080/01603477.1983.11489375

VON ARNIM, R.; RADA, C. Labour productivity and energy use in a three-sector model: an application to Egypt. Development and Change, v. 42, n.6, p. 1323-48, 2011. crossrefhttps://doi.org/10.1111/j.1467-7660.2011.01741.x 


\section{Anexo}

Tabela 3: Matriz de Insumo-produto (resolvida) do RS para o ano de 1998.

\begin{tabular}{|c|c|c|c|c|c|c|c|c|c|c|c|c|c|}
\hline $\begin{array}{l}\text { MIP/RS } 1998 \\
\text { (Setores/ setores) } \\
\text { (Milhões de reais de 1998) }\end{array}$ & 1 & 2 & 3 & 4 & 5 & 6 & 7 & 8 & 9 & 10 & 11 & Demanda & $\mathrm{VBP}^{*}$ \\
\hline Agropecuária (1) & 1137,1 & 3789,0 & 0,0 & 13,1 & 4,6 & 6,1 & 0,8 & 0,2 & 0,0 & 28,9 & 158,7 & 4239,7 & 9378,1 \\
\hline $\begin{array}{l}\text { Indústrias de transformação } \\
\text { e extrativa (2) }\end{array}$ & 666,1 & 4967,1 & 0,0 & 1434,3 & 503,1 & 671,0 & 90,8 & 18,9 & 0,0 & 173,5 & 854,5 & 24119,7 & 33498,9 \\
\hline $\begin{array}{l}\text { Produção e distrib. de } \\
\text { eletric. e gás, água (3) }\end{array}$ & 22,2 & 295,2 & 650,5 & 0,0 & 56,8 & 16,0 & 13,2 & 20,4 & 0,0 & 191,2 & 41,4 & 1152,5 & 2459,5 \\
\hline Construção civil (4) & 0,0 & 0,0 & 0,0 & 411,0 & 0,0 & 0,0 & 0,0 & 0,0 & 218,9 & 0,0 & 0,0 & 6745,5 & 7375,4 \\
\hline $\begin{array}{l}\text { Comércio e Serviços de } \\
\text { Manut. e Reparação (5) }\end{array}$ & 49,1 & 1874,3 & 0,0 & 58,2 & 296,8 & 0,0 & 0,0 & 0,0 & 0,0 & 0,0 & 0,0 & 6296,5 & 8575,0 \\
\hline $\begin{array}{l}\text { Transporte, armazenagem e } \\
\text { correio (6) }\end{array}$ & 0,0 & 176,3 & 0,0 & 0,0 & 210,9 & 1053,6 & 120,6 & 0,0 & 0,0 & 31,2 & 46,4 & 3309,7 & 4948,7 \\
\hline Serviços de informação (7) & 0,0 & 145,8 & 3,4 & 15,7 & 82,1 & 62,1 & 30,7 & 78,3 & 0,0 & 85,4 & 62,1 & 1345,1 & 1910,8 \\
\hline $\begin{array}{l}\text { Intermediação financeira, } \\
\text { seg. e previdência (8) }\end{array}$ & 292,4 & 863,0 & 60,1 & 139,0 & 376,5 & 237,8 & 116,4 & 616,3 & 287,7 & 372,7 & 216,8 & 982,7 & 4561,2 \\
\hline $\begin{array}{l}\text { Atividades imobiliárias e } \\
\text { aluguéis (9) }\end{array}$ & 0,0 & 37,4 & 0,0 & 22,8 & 200,8 & 47,3 & 40,4 & 151,3 & 0,0 & 51,1 & 43,4 & 7113,5 & 7707,9 \\
\hline $\begin{array}{l}\text { Administração, saúde e } \\
\text { educação públ. (10) }\end{array}$ & 0,0 & 0,0 & 0,0 & 0,0 & 0,0 & 0,0 & 0,0 & 0,0 & 0,0 & 0,0 & 0,0 & 10795,2 & 10795,2 \\
\hline Outros serviços (11) & 0,0 & 114,0 & 52,6 & 190,1 & 286,5 & 272,5 & 368,1 & 630,2 & 0,0 & 1191,0 & 231,1 & 4787,8 & 8123,9 \\
\hline Valor Adicionado & 6158,7 & 15857,2 & 1502,2 & 3474,5 & 6225,0 & 2172,8 & 1041,5 & 2954,4 & 7191,8 & 8341,1 & 5420,6 & & \\
\hline Importações e impostos & 1052,5 & 5379,8 & 190,7 & 1616,6 & 331,9 & 409,6 & 88,2 & 91,3 & 9,5 & 329,0 & 1048,9 & & \\
\hline Valor bruto da produção & 9378,1 & 33498,9 & 2459,5 & 7375,4 & 8575,0 & 4948,7 & 1910,8 & 4561,2 & 7707,9 & 10795,2 & 8123,9 & & \\
\hline
\end{tabular}

Fonte: Elaboração dos autores. *VBP é o valor bruto da produção. 
Tabela 4: Matriz de Insumo-produto (resolvida) do RS para o ano de 2008.

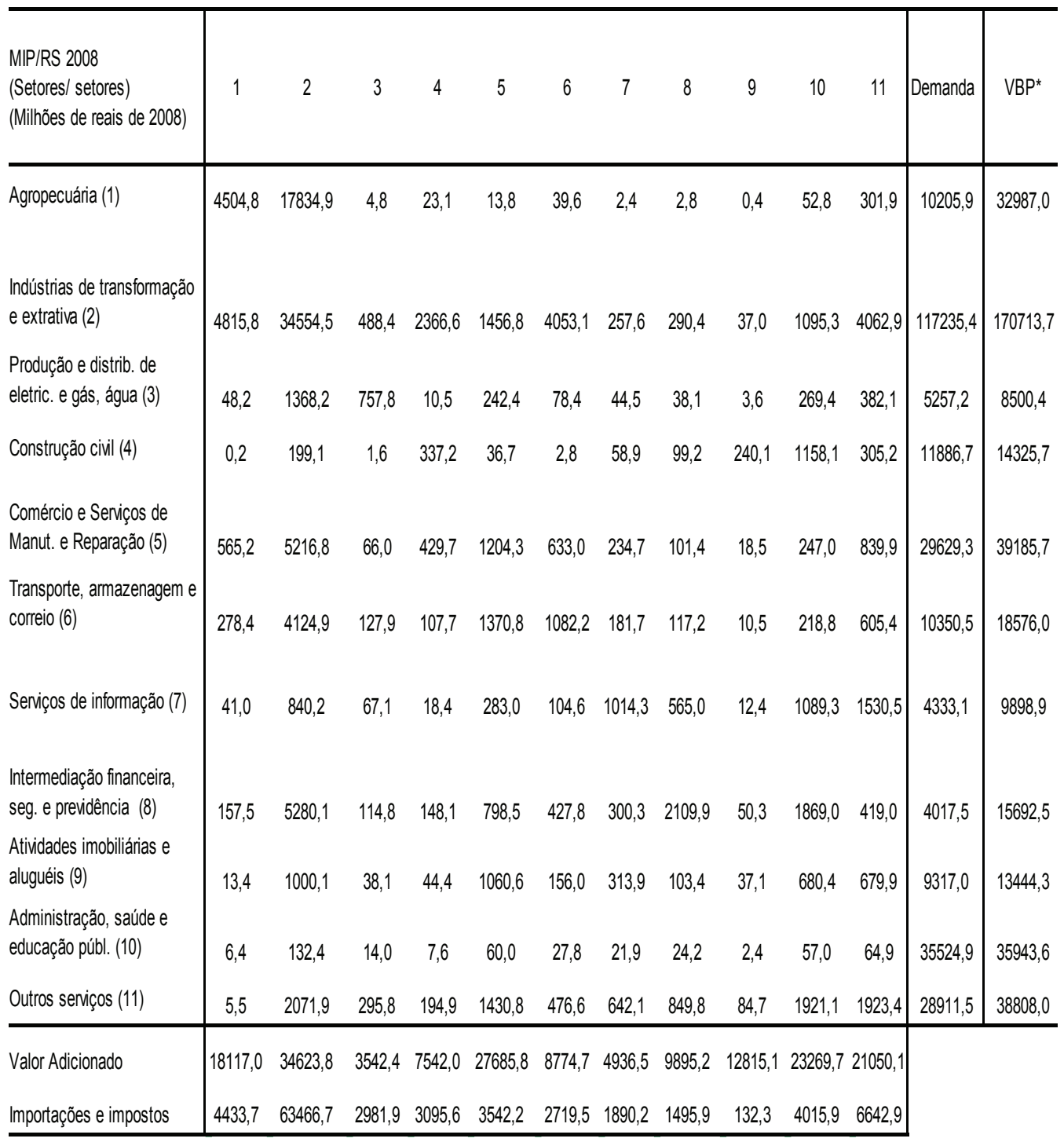

Fonte: Elaboração dos autores. * VBP é o valor bruto da produção. 
Tabela 5: Índices de ligação de Rasmussem e coefificientes de dispersão de Bulmer-Thomas da economia do Rio Grande do Sul - 2008

\begin{tabular}{|c|c|c|c|c|c|c|c|c|}
\hline \multirow{2}{*}{ Discriminação } & \multicolumn{4}{|c|}{ Encadeamento para trás } & \multicolumn{4}{|c|}{ Encadeamento para a frente } \\
\hline & índice & Ranking & Dispersão & Ranking & índice & Ranking & Dispersão & Ranking \\
\hline Agropecuária & 1,065 & 3 & 2,721 & 5 & 1,047 & 5 & 2,775 & 6 \\
\hline $\begin{array}{c}\text { Indústria extrativa } \\
\text { mineral }\end{array}$ & 1,031 & 4 & 2,381 & 12 & 0,739 & 11 & 3,408 & 1 \\
\hline $\begin{array}{l}\text { Indústria de trans- } \\
\text { formação }\end{array}$ & 1,220 & 1 & 2,450 & 10 & 1,427 & 1 & 2,056 & 11 \\
\hline Energia & 0,918 & 10 & 3,170 & 2 & 1,393 & 2 & 2,029 & 12 \\
\hline Construção civil & 1,002 & 7 & 2,496 & 9 & 0,800 & 10 & 3,163 & 3 \\
\hline $\begin{array}{l}\text { Comércio e servi- } \\
\text { ços de manutenção } \\
\text { e reparação }\end{array}$ & 0,918 & 11 & 2,754 & 4 & 0,955 & 7 & 2,632 & 8 \\
\hline $\begin{array}{c}\text { Transporte, armaze- } \\
\text { nagem e correio }\end{array}$ & 1,089 & 2 & 2,418 & 11 & 0,978 & 6 & 2,657 & 7 \\
\hline $\begin{array}{l}\text { Serviços de infor- } \\
\text { mação }\end{array}$ & 1,029 & 5 & 2,647 & 6 & 0,948 & 8 & 2,895 & 5 \\
\hline $\begin{array}{l}\text { Intermediação } \\
\text { financeira, seguros } \\
\text { e previdência com- } \\
\text { plementar e servi- } \\
\text { ços relacionados }\end{array}$ & 0,995 & 8 & 2,856 & 3 & 1,074 & 3 & 2,620 & 9 \\
\hline $\begin{array}{l}\text { Atividades imobili- } \\
\text { árias e aluguéis }\end{array}$ & 0,755 & 12 & 3,293 & 1 & 0,846 & 9 & 2,906 & 4 \\
\hline $\begin{array}{c}\text { Administração, } \\
\text { saúde e educação } \\
\text { públicas e segurida- } \\
\text { de social }\end{array}$ & 0,958 & 9 & 2,529 & 7 & 0,732 & 12 & 3,398 & 2 \\
\hline Outros serviços & 1,021 & 6 & 2,521 & 8 & 1,061 & 4 & 2,408 & 10 \\
\hline
\end{tabular}

Fonte dos dados brutos: Sá (2014) e Morrone(2015). 
